\title{
IDEA OF IMPLEMENTATION COMMUNICATIVE APPROACH (SUPPORTED BY 3PS METHOD) IN UKRAINIAN STUDENT LANGUAGE TRAINING
}

\begin{abstract}
Anna Zinkevych
doi: 10.18355/PG.2019.8.1.9

Abstract

The modern world is turning into a unified society and learning of foreign languages may help Ukrainian students enter both scientific and professional international life, facing fewer obstacles. Obviously, the language learning process should be brought in line with the latest approved standards. In order to achieve the set goals, educational methods should be reinforced by the help of contemporary methodological ideas and tools. The article develops necessity to use innovative trends in teaching English, so that students' speaking skills are being improved whilst the desire of conveying the personal point of view is being actively encouraged.
\end{abstract}

\section{Key words}

CLT, speaking skills, international standards, communicative competence

\section{INTRODUCTION}

In the modern and to some extent unified society both professional and scientific worlds require knowledge of English which begs the question of efficient and real-life based teaching methodologies applicable for higher educational establishments. Mastering and constantly improving foreign language skills, graduates of higher educational establishments increase their chances of getting prospective employment opportunities and entering the scientific world of innovations and inventions presenting own achievements on an international scale. High level of fluency and accuracy of English demands appropriate teaching methods and approaches although it also depends on taking into consideration material selections the same as students' acceptance and expectations.

A communicative approach to foreign language teaching (CLT) is not as contemporary as it is thought to be. John Roberts said about the CLT: "The king is dead! Long live to King!" (Roberts, 2004). Obviously he meant the primary idea of the approach, teaching for communication. Since the ancient times of human era such great scholars as Erasmus tried to convey the real meaning of language as a social tool for solving problems by means of communication (Roberts, 2004). After hundreds of years of evolution teaching methods have been changed and supported by linguists appealing to grammatical accuracy and lexical diversity, which is absolutely appreciated. However historians haven't proved that the human brain has drastically changed, given us some special sophistication or smartness in the question. Vice versa human beings of the 21 century are less adequate communicators aimed at problem-solving due to technical progress which influences usage of 
language in a certain way. Reasonably, teachers and scholars are apostrophizing the egress of the idea in order to emphasize the importance of communicative competence within the frames of worldwide interaction by means of improving existing techniques and developing modern ones based on contemporary needs and generously updated with regards of latest technologies.

Dealing mainly with school-leavers, present students and graduates, I noticed obvious problems in thoughts conveying and their ability to apply obtained knowledge of the foreign language for task solving or involvement in spontaneous conversations. No difference was traced in work with wellversed English students or less successful language users. The proof of the pudding is in the eating, isn't it? First and foremost, the English language is a must for efficient socializing between world communities. Thuswise more profound development of communicative competence is a desperately sharp necessity for higher educational institutions in Ukraine. Neither brilliantly drilled commands in grammar, nor extremely rich vocabulary bulk can create a favorable environment for breaking psychologically reinforced language barrier while facing alien culture, mentality, and without any doubts very different language structure and speaking manner in comparison with native language.

\section{METHODS}

140 This study reveals some primary objectives in English teaching as a foreign language within the context of educational reforms in Ukraine, i.e., the pressing need for communicative approach application in the state higher educational establishments proved by its strong points; taking appropriate decisions on support program to CLT aimed at reducing psychological discomfort and setting clear focus of teachers competence and responsibility. The mentioned questions are thoroughly analyzed, discussed below and some solutions are also outlined.

\section{RESULTS}

Our country is facing plenty of hurdles on its way to European integration, adopting newly-built reforms, struggling throughout financial and political problems, fighting for its sovereignty and independence. Nevertheless the perspective of educational reform is supposed to be the milestone in the European direction which must reassure equal membership in the community of developed countries on condition of intellectual development.

"The education reform envisions a systemic transformation of Ukraine's education sector into an innovative environment in which students develop skills to independently acquire and apply knowledge to real-world situations, and where scientists have the opportunities and resources to conduct research and directly influence the country's socioeconomic situation."(Gov.UK. 2017) 


\subsection{The urgent necessity of CLT implementation in accordance with international standards}

Anyway worldwide collaboration demands confident English language commands as well as appropriately developed knowledge and skills in other professional areas. The latest surveys, conducted among school-leavers and present students, show their enhanced interest in studying foreign language although most of the interviewees expose grave concerns about effective methods of gaining the necessary range of skills. Being taught grammar rules or an adequate number of vocabulary units the bigger half of respondents still experiences insuperable formidability towards speaking language naturally. Intensive usage of traditional methods such as grammar translation, audiolingual and others which prevail in Ukrainian educational idea fail to satisfy the most urgent students' needs. However private educational institutions designed for foreign language teaching tend to use more devious methods, for example Computer Assisted Language Learning (CALL) or Suggestopedia in order to forward the set goals. Survey results neither in the provenance of sophisticated and unusual approaches offered to Ukrainian learners nor in rejecting traditional ways used constantly in schools and higher educational establishments. In interviewees' opinion hours of independent work in the frames of CALL method is the incredibly time-consuming mode of work which may result mainly in dealing with certain skills, whilst rather relaxing learning environment and forecasting ability to soak up language intrinsic to Suggestopedia appear to be fruitless. Otherwise both teachers and learners should be desperately focused on creating more enabling conditions for the cultivation of fluency and accuracy in speech. Improper accuracy may be rather insidious in the same manner that overrated accuracy can extinguish any kind of natural spontaneity; completely blocking interaction with more proficient interlocutors.Do not number individual sections and subsections, the template does it automatically.

Without any doubts it is possible to indicate that long-lasting inactivity and certain hesitations have already led to less trust from students. They tend to postpone the process of language studying to the exact moment of pressing need and give some reasonable arguments by means of outlining existing drawbacks of present teaching system and rejection to spent time on gaining extra knowledge. Paying attention to only primary areas of expertise, students of higher educational institutions in this regard significantly diminish studying of English language automatically accept it as a secondary necessity. Ukrainian hard-liners on all possible areas, who are highly appreciated all over the world, therefore can artificially lengthen their way upwards career leader due to such often fallacy. The delayed issue of studying English, ignorance of opportunities provided by universities and rather a mistrustful attitude may be a reflection of the following problems: inexpediently mandated timing for studying a foreign language, educational programs which are far from competence level consideration and are rarely aimed at mastering and applying life-based skills. These sort of weaknesses are mainly triggered by lack of technical equipment (almost in regions), legislative peculiarities, teachers' burden to be Jack of hundred crafts which 
prevail better quality and successful implementation of new approaches, and finally by inappropriate funding.

During the presentation of scientific project 'Fulbright' in the National University of Food Technology we had the honor to discuss the most important issues with the participant who came from the USA and had taught English to Ukrainian students at Lugansk university in Vinnytsia. Discussing and comparing our experiences, techniques and modes of work we both came to the conclusion that excessive focus on estimation process and the pressure of studying success rate may be key points to generate hurdles in conveying own viewpoints. Well noticeable fear to state wrong things or break accuracy of utterance is provoked by the possible harmful impact on success rate and in its turn can cause psychological resentment to language and result in strongly developed language barrier also concerning the general speaking ability of the individual. This tendency can be depicted as a disastrous for the country primary and initial aim of which is European integration the same as an international acknowledgment. The role of English is significant for further achievements first of all as a communicational tool.

"In language teaching three broad aims can be distinguished: the social, the artistic (or literary), and the philosophical. The first aim demands that language should be regarded as a form of social behavior and a type of communication. The artistic aim treats language as a vehicle for creativity, demanding both appreciations of creative activity and the creative activity itself ... The philosophical aim demands training in analytic techniques and often confuses linguistics with language teaching. " (Kelly, 1969)

It might be claimed that since mid and later the $20^{\text {th }}$ century the teaching of English was to be pursued for social and communicative purposes. English was to be regarded as a social tool for the carrying out negotiations and different types of interactions by means of language, considering empirical consequences of which, however, might be far beyond linguistic field (Roberts, 2004). So we draw an inference from above-mentioned observations that CLT is the most reasonable tool for studying English as a mean of communication in the forthcoming future. Primarily and mainly this approach raises the question of life-based communicative competence and appreciates the importance of consistent opinion expression. In addition some implicit analytical techniques of language usage, which are indispensable in negotiation and achieving discussion goals, are efficiently trained throughout the performance. Moreover CLT is expected to be a compilation of the best and most widespread language teaching techniques which are attained in accordance with a certain level and purpose, taking into account necessity to drill, master and perform gained ability in an artificially created environment of "language immerse".

For the sake of fairness, it would be worth noting that Southeast Asian countries faced a lot of hurdles caused by local conditions while making some attempts to implement CLT. By reference to Saeed Ahmad it may be stated that some peculiar difficulties were connected with the locally sanctioned teacher-centered system where the authority of the teacher has 
local and cultural approval (Saeed, Congman, 2013). Over and above the predominance of text-centered and grammar-centered practices for example in Korea does not provide a basis for the student-centered, fluency-focused, and problem-solving activities required by CLT ( $\mathrm{Li}, 1998)$. Despite some cultural, economic or other peculiarities CLT is widely used for studying foreign languages in plenty of developed countries. Thus we are hopefully craving for some legislative changes within the context of education reform, allowing appliance of this approach in Ukrainian educational institutions in order to train highly-skilled specialists responsible for the reputation of our country far beyond its borders.

\subsection{CLT as the key methodology of teaching and learning language naturally drawing on its main advantages}

The CLT technique is supposed to be the most popular technique widely used and accepted to classroom-based foreign language teaching.

"It emphasizes the learner's ability to communicate various functions, such as asking and answering questions, making requests, describing, narrating and comparing. Task assignment and problem-solving - two key components of critical thinking - are the means through which the communicative approach operates." (Jonathan, 2016)

Grammar is taught in the context or via solving the problem rather than in isolation which is typical for direct method. Detailed corrections in favor of the theory are not recommended, thus frequent use of correct speech sample will develop accurate and fluent speech throughout communicating in the language rather than analyzing it.

CLT includes task-based activities grounded in task-based learning which is a refinement of the communicative approach. Language is taught by means of focus on the completion of the specifically designed task. This type of learning environment is devoted to specific topics, i.e. ecology, security, a computer, etc., and usually offer time limits to work out one thematic unit. Familiar language is used actively although varieties of assignments make students acquire new structures, forms and vocabulary because deep involvement and desire to achieve the communicative aim are predisposed by distinctly conceptualized tasks and situations. Step-by-step learning of one thematic unit usually culminates in a final project such as a written report, presentation or simulated conference on a certain subject.

Among plenty of positive moments just like using authentic materials, encouraging to negotiation, asking and answering questions, developing written commands of language the most remarkable and owing to this the most favorable for the learning process is the dedication to and reliance on principled eclecticism which means freely implementation of all earlier developed methodologies and approaches in accordance with set goals upon condition of creative task design. 


\subsection{Supportive practices which imply efficiency enhance and reduce psychological unease}

Speaking from its own experience, it was convinced that Ukrainian students and probably those from other post-soviet countries inclined to feel psychological discomfort and fear of being asked questions, involved into the conversation without any preparation and as a result failing the task completion. Students are terrified by dealing with authentic materials from the earliest stages and idea of excluding drilling grammar tasks. In other words I faced very strong resistant of getting new experiences and disability to be relaxed and spontaneous without predisposition to stability and common layout of the studying process. This sort of behavior is assumed to be the result of the historical development of these countries and a rather specific educational system based on idealistic standout images. As a pertinent contribution to the struggle against deeply planted and thoroughly grown-up stereotypes and inhibitions, it is possible to suggest 3Ps or PPP method. The conceptual idea underpinning the 3Ps method is embedded within the gradual helicoid mastering of necessary skill, approaching the point of readiness for CLT technique implementation.

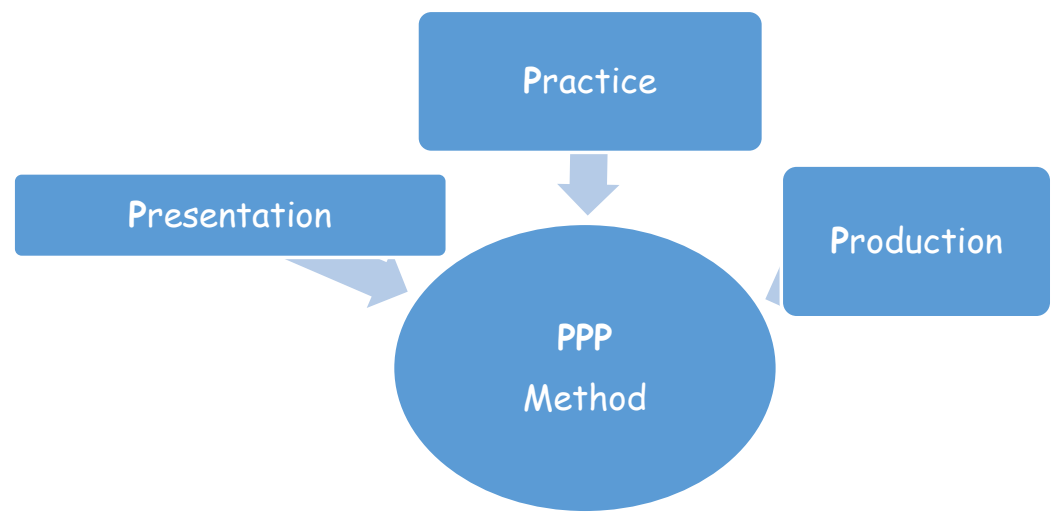

Picture 1. Diagram of stages in 3Ps Method

3Ps method is common in the SEE TEFL certification course and could be characterized as a common-sense approach to teaching. Such a gradually increasing mode of work enables us to attain necessary relaxed and friendly atmosphere on purpose of stress decline and efficiency extension. It includes 3 phases, nominated as Presentation, Practice and Production.

\subsubsection{The first stage is Presentation}

In order to achieve full stage completion, it is very important to take into consideration 4 key things: 
- $\quad$ Attention in the classroom may be attained via interesting language presentation, exaggeration of facial expressions, gestures and miming is recommended (the last points are used in favor of stress reduction and relaxation).

- $\quad$ Perception and language grading. White boards, different colors for emphasizing a variety of ideas, non-ambiguous images are encouraged to improve visual perception. The range of specially designed tasks can also evoke tactile perception which may be highly appreciated by a lot of students. A graded language is a tool for interplay thus a teacher needs to be very distinct while giving instructions, avoid unreasonably complicated words and expressions, speaking on students' level.

- $\quad$ Target language understanding. Success is embedded by choice of appropriate language to understand, check the level of understanding disregarding direct questions but relying on contextual activities.

- $\quad$ Short-term memory is usually achieved in the classroom. Learners will have to retain a clear memory of units, worked out during presentation phase, to be able to use them further. In order to provide engagement, it is necessary to consider different memorization modes.

\subsubsection{The second stage is Practice}

Practice

$\begin{array}{ll}- & \text { Practice validity } \\ - & \text { Pre-learning } \\ \text { - } & \text { Volume of practice } \\ \text { - } & \text { Success orientation } \\ \text { - } & \text { Issuing instructions and managing activity }\end{array}$

\section{Picture 2. Diagram of relevant phases during the second stage}

It can be depicted as a final "rehearsal" of certain behaviors on the purpose of learning consolidation and performance improvement. Practice validity implies different forms dictated by target language. Food vocabulary items can be practiced via the structure of dialogue. An additional and rather a helpful tool is pre-learning, described as a control check-up of full understanding and involvement. Practicing without any confirmation of acceptance may be quite stressful and destroying for confidence. Volume is also a significant question on this stage. Practicing opportunities should be correlated with a number of students and their level in order to reassure everybody's participation and practicing the given language not the level of sound, thus individual worksheets should be arranged. Success orientation can be guaranteed in case of following some rules: issuing activity instructions in a clear and unambiguous way, strongly supported by 
demonstration and visuals; managing the process constantly; collecting tasks of proper level for everyone to complete and cheering encouraging feedback is obligatory.

\subsubsection{Production is the last and most challenging stage however the most rewarding}

This phase dictates minimal teacher assistance but just supervision and encouragement are concerned. The volume of production is measured by students" first tentative "strokes" on their own demonstrated while participating team speaking, pair activities and debating. The validity of production is attained by means of specially tailored tasks which demand production of necessary language although students having a high level of language may be asked for variation. It would not be odd to remind of the urgent need to simulate real-life situations, implement task-based approach suitable for discussed topics within the frames of contextualization. Student autonomy is an undisputable condition of successfully completed production stage. Cleaned whiteboards and put away studying materials from the desks should imitate natural speaking environment which is rather severe and hostile because of plenty disturbing sounds, possibility to be interrupted or necessity to speak surrounded by background activities.

In my opinion such a spiral, slightly increasing pace of work is the most acceptable in terms of softening CLT approach by means of compensative PPP method nature in favor of comfort psychological climate and relaxed 146 atmosphere of the lessons. I am concerned that students' comfort is a really significant moment which allows earning their trust, helping to encourage their full involvement and positive feedback accordingly.

\subsection{Set framework of teacher competence}

On the one hand noticeable funding, financial problems in the sector of higher education the same as an economic crisis may influence implementation of above-mentioned techniques negatively but on the other hand teachers' unawareness of appropriate facilities, lack of training and very few incentives offered as a reasonable reward for a professional job can totally diminish the process. A lot of aspects in CLT, claimed to be effective but largely performance and mastering depend on excellence in teachers. Unfortunately chasing an idea of total compliance with international standards some may conceal the fact of not having the faintest idea about CLT, own disability to customize widely used approach to student needs behind beautiful words and solemn theories of its inefficiency.

Poor competence is equal to illiterate students accordingly. Inadequacy during the process of mistake correction results in fluency which has nothing in common with accuracy, so as a consequence students fail to achieve communicative competence, distorting own utterances. On the contrary some authoritarian tendencies and pushy behavior can demolish even the faintest "strokes" of speaking. Therefore teacher's ability to correct mistakes delicately and gently without shrinking or breaking student statements is the 
key to successful teaching practice which is thought to be a real art of subtleties. Compensatory competence is a crucial skill for a student in order to let them off an embarrassing situation in real-life communication.

Another frequent misconception constitutes poorly synchronized and systematized grammar explanations and mastering as it has very little correlation with communicative competence under real conditions. Modern books designed for learning English truly tend to place less weight on drilling grammar phenomena which is acceptable only in case of living in the nativespeaker environment. If this were not the case, students require more profound discourse on grammar peculiarities and independent work should be excluded as an option in the virtue of striking differences between grammar structures of Ukrainian and English languages.

A frequently heard argument, though fundamentally flawed, is that the communicative approach means only speaking activities and just convenient relaxed conversations. However harmonized and fruitful development of communicative competence means equal mastering of all language aspects including writing in order to approach visible progress in speaking. Moreover teacher should speak properly on purpose of presenting either something new for students or mastering appropriate skill or structure, just small talks or spotless games cannot be claimed communicative approach.

It is strongly argued that the use of native language demolishes the idea of CLT and disgraces all the efforts taken to simulate the concept of full language immerse. First and foremost communicative approach is aimed at efficiency, thus a critical need to use the native language to provide an adequate explanation of grammar rule is obviously justified.

Of course the strong increase of successful implementation should be enabled by means of authentic materials and attempts of creating a natural atmosphere at the lessons as well as independent work encouragement which will help to preserve the feeling of so-called immerse beyond the studying process.

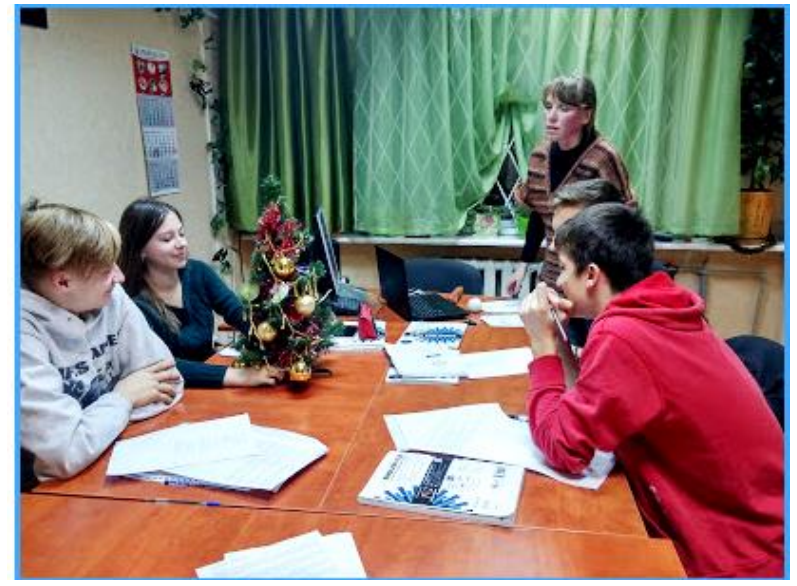

Picture 3. Attaining of a friendly, relaxed atmosphere

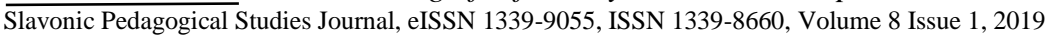


Among discussed things the last but obviously worth mentioning is a psychological side of teaching any foreign language. It is crucial for teaching Ukrainian students in terms of noticeable communicative problems and phobic attitude to conveying own thoughts, debating or asserting their rights the same as negotiation. Teachers' incompetence on an equal basis with restraining and authoritarian behavior may result in heavy psychological disgrace to studying. Frequently underlined prevailing position of the teacher may be harmful for student confidence and can provoke irresponsiveness and lack of interaction especially in the case with adults and students of higher educational establishments who are mature enough to realize own failures sharply.

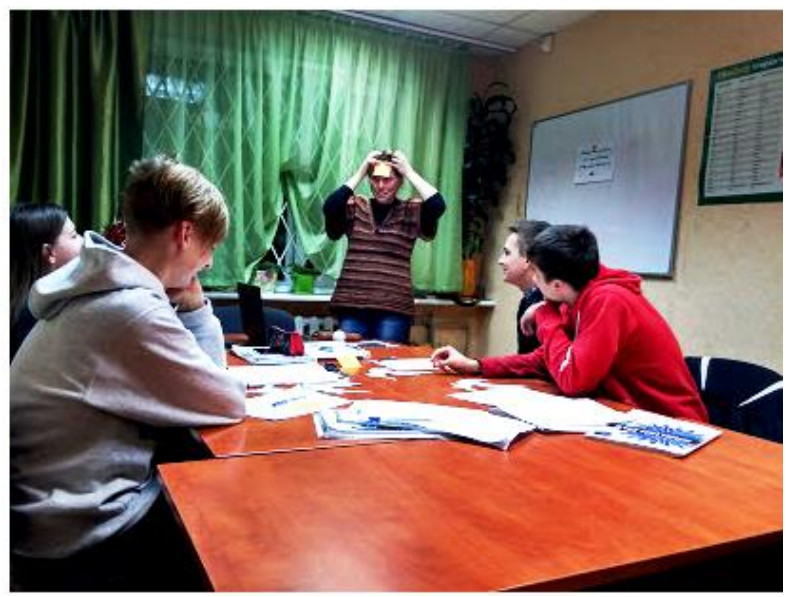

Picture 4. Teachers' own inspiration and involvement is the best model to follow

This is exactly the reason a teacher should demonstrate equality of positions and sincere desire to share own knowledge. It is important to avoid talking about engagement in the most disengaging way, using common clichés "You need... You have..." Besides attempts to prove the importance of something explained by getting real-life examples are highly appreciated. The manner of speaking should not be artificial, playing with intonation, voice, vivid and vibrant gestures are necessary to become a master storyteller and create engagement. Teachers' own involvement awakes student's curiosity, evokes questions. It is crucial to remember that trials and errors embrace our horizons.

\section{Conclusion}

In summary it would be wise to admit the omnipresent importance of English language in modern society, it's remarkable without any exaggeration role in worldwide communication. Nowadays good knowledge of English is a key to unlock every door either in the world of science or in the area of business negotiation. Furthermore still developing standards of unification and cosmopolitan-minded tendencies are quite obsessing among 
young people. Everybody realizes a strong necessity to master English commands in order to be a competitive professional who may expect more promising, prospective employment.

After all, our country is looking forward to becoming a part of the European community on equal conditions both in economic prospects, scientific inventions and intellectual achievements. Such high expectations demand adoption of severe reforms including the educational sector. Therefore education reform desperately needs revision and thorough reconsideration which should yield total compliance with common international standards in all aspects and targeting primary citizen requirements. Thus communicative approach is expected to be the most fruitful and justified "investment" on the long-lasting basis in favor of growing intellectual potential and the general image of our country on the international scene.

Consequently it would be useful to outline the main characteristics of CLT from the developmental perspective of issues in the possibility to think by means of learned language under real-life circumstances. Thus the creative, task-based approach to the design of activities can increase the speed of verbal interaction inducing mental reflection by means of studying language on a natural basis. The communicative approach emphasizes the significance of using language, given the possibility to express emotions, opposing concepts, give sensible advice or make a motivation speech by the aid of studying the language. The communicative approach does not promise a quick result. It assumes to some extent phased training culminating in vast, reliable knowledge.

All in all, CLT is said to be a psycholinguistic approach rather than pure linguistic which brings out increased attention to psychological aspects of studying a foreign language. CLT allows and even recommends implementing different methods, designed according to its main principle of emphasizing communicative competence; thereby the research has resulted in applying supportive techniques such as a 3Ps method in order to minimize negative psychological impacts produced by imitation of deep language immerse. Spiral and gradual nature of which reassures students in their readiness for speaking and provides confidence in solving tasks under conditions of a realistic environment. Nevertheless not only broken rules of CLT appliance but also lack of privity the same as restraining attitude demonstrated by the teacher can cause extremely negative consequences. Students may develop a persistent aversion to studying process and fail to develop desirable language competence. In order to prevent such events, it would be worth noting the necessity of cheering up, encouragement and adequate mistake correction. Accept this; the teacher should be delicate and patient in response to going blank students. Curiosity comes first, beyond any other desires and objectives in studying. Respectively to this teachers should embrace new horizons as cultivators of curiosity and inquiry. We should celebrate failures as the steps to success, encourage challenges as main developers of inspiration. Audacious idea of perceiving new things, conquering greater heights either in language learning or inventing great Slavonic Pedagogical Studies Journal, eISSN 1339-9055, ISSN 1339-8660, Volume 8 Issue 1, 2019 
pieces must be supported by enthusiastic skepticism which is not the enemy of boundless optimism, I would rather say a perfect partner which unleashes the potential shackled in this idea.

\title{
Bibliographic references
}

GOV.UK. 2017. Ukraine Reform Conference -Government Topical Events. [Online]. 2017. [Accessed 6 July 2017]. Available Online: https://www.gov.uk/government/topical-events/ukraine-reform-conference HOWARD D. 2018. 'What is the PPP Method of Teaching English?' [Online]. 2018. [Accessed 23 June 2018]. Available Online: http://shaneschools.com/en/what-is-the-ppp-method-of-teaching-english/

JONATHANZ L. 2016. 'The Key Foreign Language Teaching Methodologies and How to Choose the Best for You' [online]. 2016. [Accessed 7 January 2016]. Available Online: https://www.fluentu.com/blog/educator/foreign-language-teachingmethodology/

KELLY, L G. 1969. Twenty-five centuries of language teaching. Rowley, Mass.: Newbury House.

LI, D. 1998. 'It's always more difficult than you plan and imagine: teachers' perceived difficulties in introducing the communicative approach in South Korea', in TESOL Quarterly, 3, 4: 677-703.

RICHARDS, J. C. 2006. Communicative Language Teaching Today, Cambridge University Press, 1-30. Available Online:

150 https://www.researchgate.net/publication/242720833_Communicative_Langu age_Teaching_Today

ROBERTS J.T. 2004. 'The Communicative Approach to Language Teaching: The King is dead! Long live the King!' in International Journal of English Studies, University of Essex, vol.4 (1), pp.1-37

SAEED A. - CONGMAN R. 2013. 'Applying Communicative Approach in Teaching English as a Foreign Language: a Case Study of Pakistan', in Porta Linguarum, № 20, 2 pp. 187-203, ISSN: 1697-7467

SAVIGNON S. - BERNS M.S. 2013. Functional approaches to language teaching: Another Look, In 'Initiatives in communicative language teaching. A book of readings', MA: Addison-Wesley, pp.3-21

VDOVIN, V. V. 2010. 'Komunikatyvnyi pidkhid yak optymalnyi zasib vyvchennia inozemnoi movy u VNZ' [Communicative approach as an effective means of foreign language learning]. Natsionalnyi universytet "Lvivska politekhnika". Available Online: http://vlp.com.ua/files/07_36.pdf.

\author{
Anna Zinkevych \\ The National University of Food Technologies, Kyiv \\ Ukraine \\ anna_zinkevych@i.ua
}

